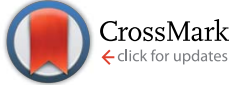

Cite this: RSC Adv., 2014, 4, 33168
Received 6th May 2014

Accepted 24th June 2014

DOI: $10.1039 / c 4 r a 04183 f$

www.rsc.org/advances

\section{Multifunctional, robust, light-weight, free-standing MWCNT/phenolic composite paper as anodes for lithium ion batteries and EMI shielding material}

\author{
Satish Teotia, ${ }^{a}$ Bhanu Pratap Singh, ${ }^{* a}$ Indu Elizabeth, ${ }^{a}$ Vidya Nand Singh, ${ }^{b}$ \\ Raman Ravikumar, ${ }^{c}$ Avanish Pratap Singh, ${ }^{d}$ S. Gopukumar, ${ }^{c}$ S. K. Dhawan, ${ }^{d}$ \\ Anchal Srivastava ${ }^{e}$ and R. B. Mathur ${ }^{a}$
}

Energy density of Li-ion batteries is marred due to the additional weight of copper, which is used as a current collector. In this work, fabrication of strong, graphitized, multiwalled carbon nanotubes (GCNTs)/phenolic composite paper using a new dispersion technique is reported. The composite paper has been used as a free-standing current collector, as well as an anode material for Li-ion batteries, because of its good electrical conductivity of $76 \mathrm{~S} \mathrm{~cm}^{-1}$. This highly thin conductive composite paper (thickness $140 \mu \mathrm{m}$ ) also shows efficient electromagnetic interference (EMI) shielding effectiveness of 32.4 $\mathrm{dB}$ in Ku-band (12.4-18 GHz). Moreover, structural and morphological studies were carried out using TEM and SEM. The flexural strength of the composite paper was $30 \mathrm{MPa}$, which is good enough for use as an electrode in batteries. The electrochemical properties of the composite paper were investigated by galvanostatic charge-discharge test. It exhibits a stable reversible specific capacity for more than 45 cycles. EMI shielding effectiveness (SE) was measured using a vector network analyzer, and the total EMI-SE surpasses the value needed for commercial applications.

\section{Introduction}

For portable electronics, aeroplanes and vehicles, batteries are required. Rechargeable batteries are best as these are cheaper and produce more power than other storage materials. Li-ion batteries (LIBs) are the most promising rechargeable batteries but the long run performance of LIBs needs to improve. LIBs typically consist of an anode (-ve electrode), a cathode (+ve electrode) and an electrolyte. Electrical energy is stored in the two electrodes in the form of Li-intercalation compounds. When charging the LIBs, the cathode releases lithium ions, which move through the electrolyte and get inserted into the other electrode; however, while discharging, the above process is reversed; i.e., Li ions move from anode to cathode through the electrolyte. The currently available battery electrodes do not have enough capacity to intercalate $\mathrm{Li}$ ions in large amounts and some of the intercalated $\mathrm{Li}$ is retained in the anode, thus

${ }^{a}$ CSIR - Network Institutes for Solar Energy, Physics and Engineering of Carbon, CSIR-National Physical Laboratory, New Delhi, India-110012. E-mail: bps@mail. nplindia.ernet.in(BPS); Fax: +91-11-45609310; Tel: +91-11-45608460

${ }^{b}$ CSIR - Network Institutes for Solar Energy, Electron and Ion Microscopy Section, CSIR-National Physical Laboratory, New Delhi, India-110012

${ }^{c}$ CSIR - Network Institutes for Solar Energy, CSIR-Central Electro Chemical Research Institute, Karaikudi, Chennai-630 006, India

${ }^{d}$ CSIR - Network Institutes for Solar Energy, Polymeric and Soft Materials Section, CSIR-National Physical Laboratory, New Delhi, India-110012

${ }^{e}$ Department of Physics, Banaras Hindu University, Varanasi-221005, U.P., India reducing its capacity after few cycles. Because of a gamut of research over the years, a considerable development in battery technologies has been observed. Graphite anodes and lithium cobalt oxide $\left(\mathrm{LiCoO}_{2}\right)$ cathodes $^{1}$ are the most commonly used electrode materials in commercial Li-ion batteries. Graphite has been commonly used as an anode material for LIBs due to its high electrical (in-plane) conductivity as a result of delocalized $\pi$-bonds, and because it has the appropriate structure for lithium ion intercalation and diffusion. ${ }^{1}$

However, graphite has a restricted capacity (one lithium atom involving six carbon atoms to form $\mathrm{LiC}_{6}$ ) and limited recharge rates. ${ }^{1,2}$ It is believed that carbon nanotubes (CNTs) can act as better anodes for LIBs. Both single and multiwalled CNTs have been examined by researchers for their usefulness as a lithium storage material. ${ }^{1,3-5}$ CNTs have excellent properties like low density, high mesoporosity, ${ }^{2}$ a high aspect ratio of $100-$ 1000 , as well as unique electrical, thermal and mechanical properties. ${ }^{6}$

In LIBs, the anode material is glued over a copper foil, which provides support to the anode. Although copper acts as a current collector and helps in charge transportation, it also increases the dead weight of the electrode, which decreases the energy density of LIBs. ${ }^{5,7}$ LIBs with a free-standing anode shall be useful for light weight electronic devices. These electrodes have a high specific energy density and capacity. Although freestanding CNT bucky papers have previously been used by several researchers and their electrochemical properties have 
been reported, ${ }^{3,4}$ they suffer from poor mechanical properties. Thus, it is very difficult to handle these electrodes in the fabrication of batteries, and there is a need to develop a light-weight free-standing anode material that has good mechanical properties. The free-standing CNT bucky papers have poor mechanical properties, which can be improved by adding a suitable binding material (polymer). If a free-standing electrode is used in place of a copper collector, it would have a lighter weight. In order to improve the electrical conductivity of CNT loaded polymers, high loading of CNTs in the polymer matrix is required. However, it is very difficult to disperse high amount of CNTs ( $>5 \%)$ in any polymer matrix by conventional techniques. The reason behind this is the presence of strong van der Waals forces between CNTs, resulting in the formation of CNT bundles. For anode fabrication, it is necessary to incorporate a large amount of CNTs into the polymer matrix in order to achieve high electrical conductivity. It has been reported that CNTs have a tendency to agglomerate when more than 1 wt $\%$ CNTs are loaded into the polymer matrix. ${ }^{8}$ Therefore, it is essential to look for a technique to incorporate higher amounts of CNTs in the matrix without deteriorating its mechanical properties. Recently, several methods have been used to produce CNT/polymer composites, which have a higher loading of CNTs. In the mechanical densification technique, vertically aligned CNTs were densified by capillary-induced wetting with an epoxy resin. ${ }^{9}$ Several other techniques have also been used, but most of them are limited by sample dimensions. A filtration system was also used to incorporate an epoxy resin into CNT bucky paper; however, complete impregnation of the bucky paper with epoxy $\operatorname{resin}^{\mathbf{1 0}, 11}$ was very difficult. Feng et al. ${ }^{\mathbf{1 2}}$ reported a mixed, curing-assisted, layer-by-layer method to fabricate a MWCNT/epoxy composite film with a high CNT loading (15-36 wt\%). In this method, two types of curing agents were used. One curing agent was responsible for the partial initial curing at room temperature to avoid re-agglomeration of the CNTs, and the other for complete curing of the epoxy resin at higher temperature to make epoxy composite films with welldispersed CNTs. In another study by Feng et al. ${ }^{13}$ up to $\sim 39.1$ wt\% SWCNT-loaded epoxy composites were produced using same layer-by-layer method, and the mechanical properties of the composite improved significantly. Macroscopic CNT composites with a high volume fraction (up to $27 \%$ ) of millimeter long and well-aligned CNTs were synthesized by Bradford et $a{ }^{\mathbf{1 4}}$ Shear pressing technique was used to process tall, vertically aligned CNT arrays into dense, aligned CNT preforms, which were subsequently processed into composites. Ogasawara et al. ${ }^{15}$ reported the fabrication of aligned MWCNT/epoxy composites by a hot-melt prepreg process. In another recent study by Singh et al., ${ }^{8}$ up to $20 \mathrm{wt} \%$ MWCNTs were uniformly dispersed in the epoxy resin and these had improved mechanical properties (prepared using prepreg technique).

In the present study, a significant modification to the prepreg preparation technique using a phenolic resin in place of the epoxy resin is reported. Phenolic resins have higher carbonization yield compared to epoxy resins and up to $46 \mathrm{wt} \%$ CNT loading can be achieved. This is equivalent to $60 \mathrm{wt} \% \mathrm{CNT}$ loading in the final carbonized composite materials, which would show excellent electrical conductivity. Thus, herein, we present a process for the fabrication of high-loading CNT/ phenolic composite paper, which can be used as a free-standing anode material and current collector in lithium-ion batteries. This electrode was tested for electrochemical performance. In addition to electrochemical properties, the electromagnetic interference shielding properties in the Ku-band $(12.4-18 \mathrm{GHz})$ frequency were also studied. The electrical conductivity, open porosity, BET surface area, flexural strength, charge discharge capacity, impedance analysis, microstructure by SEM and HRTEM, and spectroscopic analysis using Raman spectroscopy have also been studied.

\section{Experimental}

\section{Materials}

Phenolic resin obtained from IVP India Ltd. was used as a carbonaceous resin for preparing composite paper. MWCNTs were synthesized using toluene as a carbon source and ferrocene as a catalyst precursor in a home-made CVD set-up. ${ }^{16}$ The MWCNTs produced had an average diameter of $26 \mathrm{~nm}$, and the average bundle length was $\sim 350 \mu \mathrm{m} .{ }^{17}$ They were $90 \mathrm{wt} \%$ pure with 10 wt $\%$ Fe catalyst. These as-produced MWCNTs were graphitized in a high temperature graphitization furnace (under an inert atmosphere with a heating rate of $20{ }^{\circ} \mathrm{C} \mathrm{min}^{-1}$ up to $1500{ }^{\circ} \mathrm{C}$, and subsequently $10{ }^{\circ} \mathrm{C} \min ^{-1}$ up to $2600{ }^{\circ} \mathrm{C}$ ) and designated as G-CNT.

\section{Fabrication of MWCNT-phenolic composites}

$0.5 \mathrm{~g}$ MWCNT was dispersed in acetone, and these dispersed MWCNTs were added to $30 \mathrm{~g}$ of phenolic resin (Novalac type) and mixed in acetone. The suspensions were then mixed together and homogenized using a high-speed homogenizer (Miccra D-9, from ART Prozess and Labortechnik GmbH and co. KG) @ $30000 \mathrm{rpm}$ for $5 \mathrm{~min}$. The dispersed CNTs in phenolic resin were filtered in a specially designed filtration unit to form a film of MWCNT impregnated resin and dried at $50{ }^{\circ} \mathrm{C}$ for 15 min to form MWCNT-phenolic prepreg. The prepreg was compression moulded using a hydraulic press by keeping the resin between two plates at $150{ }^{\circ} \mathrm{C}$ for $2 \mathrm{~h}$. The resultant composite paper was in the form of a uniform circular disc, and the composite paper was carbonized in a programmable high temperature furnace under $\mathrm{N}_{2}$ atmosphere up to $1000{ }^{\circ} \mathrm{C}$ in steps (from room temperature to $600{ }^{\circ} \mathrm{C}$ @ $50{ }^{\circ} \mathrm{C} \mathrm{h}^{-1}$, and then $100{ }^{\circ} \mathrm{C} \mathrm{h}^{-1}$ up to $1000{ }^{\circ} \mathrm{C}$ ). The films were cut into the desired shapes for further testing, and the schematic of the complete procedure is shown in Fig. 1.

\section{Characterization}

The surface morphology of as-produced MWCNTs and G-CNT were analyzed using scanning electron microscopy (SEM) (Zeis Evo-50). HRTEM studies of as-produced and G-CNT were carried out using a Tecnai G20-stwin, $300 \mathrm{kV}$ instrument. Raman studies of the as-produced MWCNTs and G-CNT were carried out using a Renishaw inVia Raman spectrometer (UK) with an excitation source of $\mathbf{5 1 4 . 5} \mathrm{nm}$. The composite film samples were 


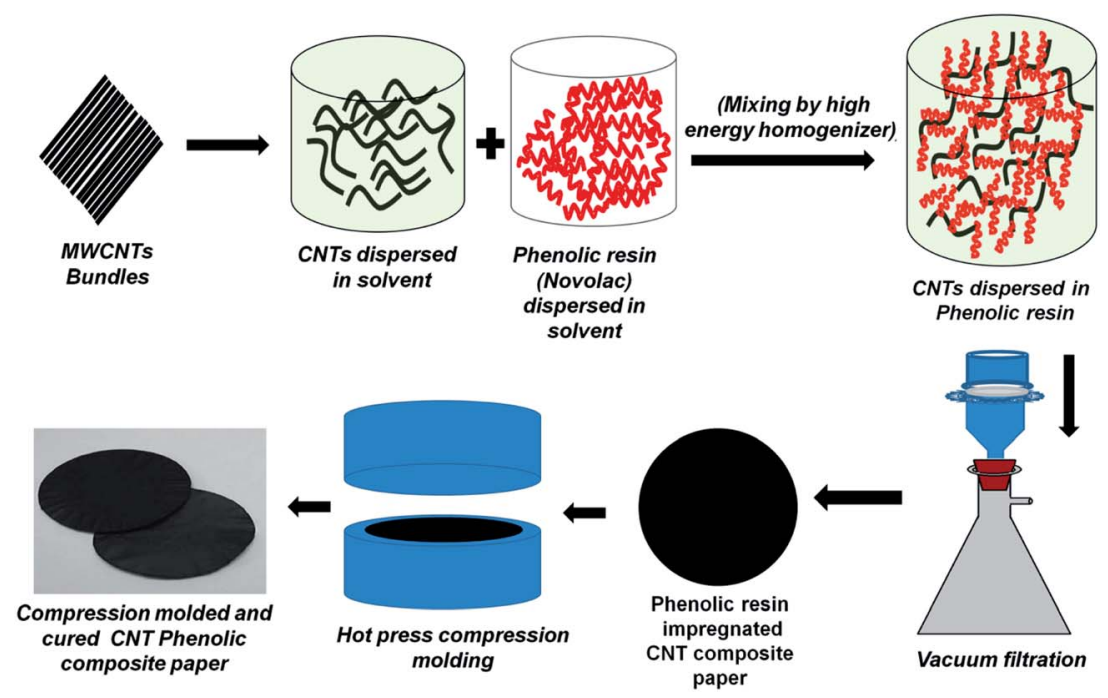

Fig. 1 Schematic of G-CNT/phenolic paper composite preparation.

cut into rectangular shapes to study their mechanical properties. The flexural strength of the CNT/phenolic composite paper was measured using an INSTRON machine (model 4411). The length of the sample was $20 \mathrm{~mm}$, and the span to depth ratio was maintained at $60: 1 .^{18}$ The cross head speed was maintained fixed at $0.5 \mathrm{~mm} \mathrm{~min}^{-1}$. For accuracy, the average of three readings was taken. Specific surface area was calculated by BET method using an autosorb iQ automated gas sorption analyzer from Quantacrome Instruments, USA (model no. ASIQM0000-4 and $\mathrm{N}_{2}$ adsorption isotherm from Germany). The electrical conductivity of the composite films $(35 \mathrm{~mm} \times 25 \mathrm{~mm})$ was measured using the dc four-probe contact method by using a Keithley 224 programmable current source and a Keithley 197 auto ranging digital microvoltmeter. The values reported in the text were averaged over five readings of voltage drops at different places on the samples. The free-standing anode for testing in a half-cell was prepared by cutting an $18 \mathrm{~mm}$ diameter circular specimen from the sample and drying it in an oven. The free-standing electrode was then assembled into a test coin cell consisting of lithium foil as a counter electrode, a separator (polypropylene film) and an organic electrolyte (1 M LiPF 6 $1: 1$ ratio of EC + DEC) in an argon-filled glove. The cell was allowed to age for $24 \mathrm{~h}$, and the cells were charge-discharged at the $\mathrm{C} / 10$ rate and within the voltage range of $0.01-2.5 \mathrm{~V}$ at room temperature to determine the electrochemical characteristics.

Electromagnetic interference (EMI) shielding effectiveness (SE) was measured (by placing the composite film in $\mathrm{Ku}$-band (12.4-18 GHz)) using a vector network analyzer (VNA E8263B Agilent Technologies).

\section{Results and discussion}

\section{Morphological and structural studies}

Fig. 2a and b show the SEM micrographs of as-produced MWCNTs and G-CNT, respectively. The quality of the MWCNTs improved after graphitization as shown by the SEM images (further confirmed by Raman studies and TEM).

Fig. $2 \mathrm{c}$ and $\mathrm{d}$ show the fractured surface of cured noncarbonised G-CNT/phenolic paper composite and carbonised G-CNT/phenolic paper composite, respectively. Cured noncarbonised composite paper shows protruding MWCNTs, which are suppressed during carbonisation. In the carbonised sample, voids (shown by arrows in Fig. 2d) are created due to the removal of the volatile material present in the resin during carbonisation.

The TEM micrograph clearly shows that as-produced MWCNTs (Fig. 3a) have some catalytic impurities on their surfaces, which were removed after graphitization at $2600{ }^{\circ} \mathrm{C}$ in induction furnace under an inert atmosphere (Fig. 3b).

The inset in Fig. 3b shows that ends of MWCNTs got opened during graphitization, which can contribute in better insertion of Li during cycling.

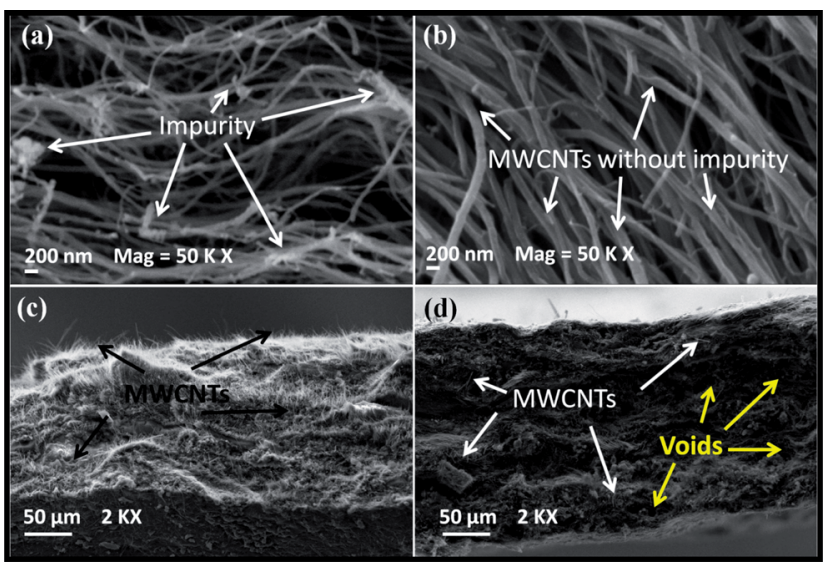

Fig. 2 SEM micrographs of (a) as-produced MWCNTs, (b) G-CNT, and (c) and (d) fractured surface of cured noncarbonised G-CNT/phenolic paper composite and carbonised G-CNT/phenolic paper composite, respectively. 


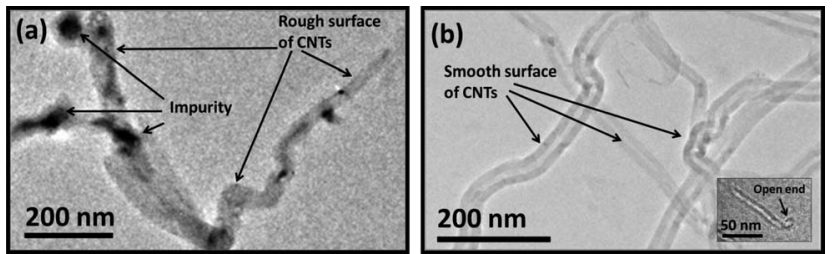

Fig. 3 TEM micrograph of (a) as-produced MWCNT and (b) G-CNT The open end of G-CNT is shown in the inset.

Raman spectroscopy is an extremely important technique that is generally used for the quick and non-destructive characterisation of all types of carbon. The Raman spectrum of MWCNT consists of three important bands, i.e. the $\mathrm{D}$ band around $1350 \mathrm{~cm}^{-1}$, the $\mathrm{G}$ band around $1580 \mathrm{~cm}^{-1}$ and the $2 \mathrm{D}$ band (also called the $\mathrm{G}^{\prime}$ band) around $2700 \mathrm{~cm}^{-1}$. The $\mathrm{G}^{\prime}$ band is an overtone of the disorder induced $\mathrm{D}$ band positioned at $\sim 1350 \mathrm{~cm}^{-1}$. Both the $\mathrm{D}$ and $\mathrm{G}^{\prime}$ bands arise due to an intervalley double resonance Raman process. The $\mathrm{D}$ band phonon scattering is a second order process intermediated by the defect, while the $\mathrm{G}^{\prime}$ band occurs due to scattering by two phonons and does not need any defects for activation. ${ }^{19}$ The $D / G$ intensity ratio $\left(I_{\mathrm{D}} / I_{\mathrm{G}}\right)$ represents the most common estimation of graphitisation index. This ratio monitors the amount of structural defects, or the extent of deviation of the crystalline arrangement from a perfect hexagonally organised planar carbon network. The $I_{\mathrm{D}} / I_{\mathrm{G}}$ ratios for as-produced and G-CNT (Fig. 4) are 0.36 and 0.22 , respectively. The significant reduction in the $I_{\mathrm{D}} / I_{\mathrm{G}}$ ratio is due to an increase in the crystallinity of the structure and a reduction in the disorder of the structure. The $\mathrm{G}^{\prime} / \mathrm{D}$ intensity ratio $\left(I_{\mathrm{G}^{\prime}} / I_{\mathrm{D}}\right)$ is very sensitive to the overall crystalline quality of the graphitic network and enhances with increasing mean inter-defect distance and/or long-range ordering. ${ }^{20}$ The better quality high value of $I_{\mathrm{G}^{\prime}} / I_{\mathrm{D}}$ (3.88 for GCNT and 2.81 for as produced CNTs) of MWCNTs is required where the organisation of $\mathrm{C}$ atoms becomes close to ideal. ${ }^{20}$

Table 1 summarizes the different properties of the composite paper. From the table, it can be seen that the sample is thin and the thickness decreases after carbonization. Composite samples have sufficient mechanical strength (flexural strength $47 \mathrm{MPa}$ for noncarbonized samples and $30 \mathrm{MPa}$

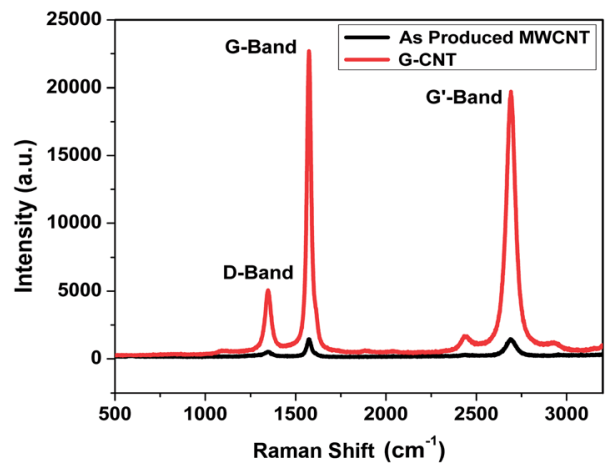

Fig. 4 Raman spectra of as-produced MWCNTs and G-CNTs. for carbonized samples). During carbonization, some volatile substances evaporate, resulting in a decrease in the density of sample. It becomes slightly porous, and the thickness decreases due to shrinkage, but the conductivity and CNT content get enhanced. The overall CNT content is the same in both the cases; however, due to the removal of volatile substances, the percentage of CNTs in the carbonised sample got increased, which improves the conductivity from $37 \mathrm{~S} \mathrm{~cm}^{-1}$ to $76 \mathrm{~S} \mathrm{~cm}^{-1}$ after carbonization.

The specific surface area of the carbonized composite sample was $167 \mathrm{~m}^{2} \mathrm{~g}^{-1}$. A larger surface area provided more sites for insertion of $\mathrm{Li}$ ions.

\section{Electrochemical performance of anode}

The charge discharge curve for samples cycled between $0.01 \mathrm{~V}$ and $2.5 \mathrm{~V}$ at the $\mathrm{C} / 10$ rate is shown in Fig. 5 .

The $1^{\text {st }}$ charge delivers $408 \mathrm{~mA} \mathrm{~h} \mathrm{~g}^{-1}$ and the subsequent discharge capacity is $115 \mathrm{~mA} \mathrm{~h} \mathrm{~g}{ }^{-1}$. The large irreversible capacity of $293 \mathrm{~mA} \mathrm{~h} \mathrm{~g}^{-1}$ is due to (i) the initial decomposition of the electrolyte at the electrode surface, which forms a solid electrolyte interface (SEI) and (ii) lithium being irretrievably trapped in the carbon matrix. The discharge capacity after 47 cycles is $147 \mathrm{~mA} \mathrm{~h} \mathrm{~g}^{-1}$, which is in the range of general graphite based anode materials. This is due to the high surface area of $\sim 163 \mathrm{~m}^{2} \mathrm{~g}^{-1}$ of the free-standing composite paper. The fabricated free-standing anode has advantage over the powder samples as it does not need a current collector or mechanical support, which adds to the dead weight of the cell/battery. In

Table 1 Properties of non-carbonized and carbonized G-CNT/ phenolic composite paper

\begin{tabular}{lll}
\hline Properties & Non-carbonised & Carbonised \\
\hline Thickness $(\mathrm{mm})$ & 0.16 & 0.14 \\
Density $\left(\mathrm{g} \mathrm{cm}^{-3}\right)$ & 0.66 & 0.51 \\
Conductivity $\left(\mathrm{S} \mathrm{cm}^{-1}\right)$ & 37 & 76 \\
$\mathrm{CNT}(\%)$ & 45.9 & 60.6 \\
Flexural strength $(\mathrm{MPa})$ & 47 & 30 \\
BET surface area $\left(\mathrm{m}^{2} \mathrm{~g}^{-1}\right)$ & - & 167
\end{tabular}

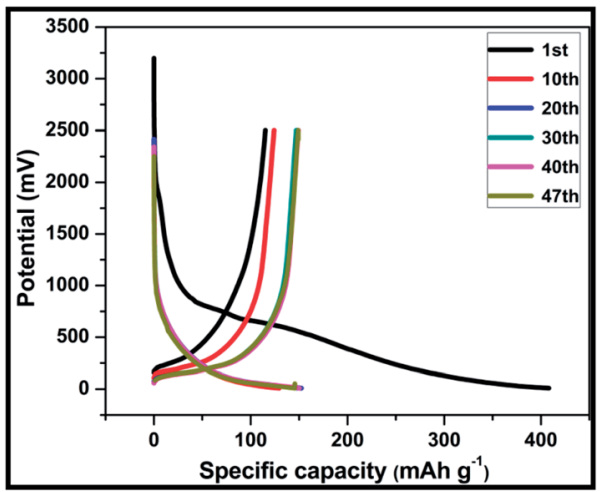

Fig. 5 Charge-discharge curve for the carbonised G-CNT/phenolic composite paper (upto 47 cycles). 
other words, these free-standing, highly conducting carbonbased anodes will have high energy density.

Fig. 6 shows the charge-discharge analysis of the sample. The capacity increases and becomes stable after 20 cycles. The increase in capacity may be due to the de-intercalation of Li ions trapped during the previous cycles. There is a capacity drop between cycle numbers 15 to 20 . It may be possible that some of the $\mathrm{Li}$ inserted into the anode did not come out in these cycles.

Fig. 7 exhibits the differential capacity curve for the chargedischarge cycle of the cell. The charge-discharge curve shows that the peak starts around $0-0.5 \mathrm{~V}$. Since this plot is considered equivalent to cyclic voltammetry, the insertion and extraction potential is derived from the peak positions. On charging, the peak potential shifts from 227 to $132 \mathrm{mV}$ for $1^{\text {st }}$ and $47^{\text {th }}$ cycles, respectively, which may be due to the very stable SEI formed. In general, the lower the insertion potential of anode materials, the higher the total voltage of the cell; therefore, the shift to a lower potential is very significant for the lithium ion battery performance.

Electrochemical impedance studies were also carried out on the samples for further understanding of cell performance. The electrolyte resistance $\left(R_{\mathrm{S}}\right)$ of the sample cell increased from 10 to $15 \Omega$, indicating a slight decrease in the ion concentration and/ or ion mobility in the electrolyte solution.

The semicircle obtained in the Nyquist plots (Fig. 8) corresponds to properties related to $\mathrm{Li}$ ion migration through the

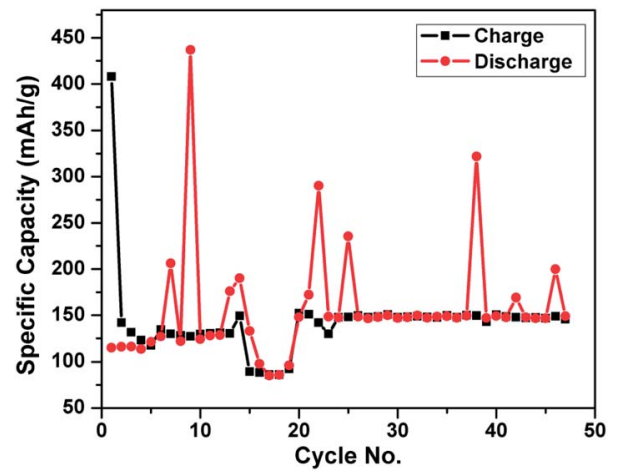

Fig. 6 Specific capacity of carbonised G-CNT/phenolic composite paper.

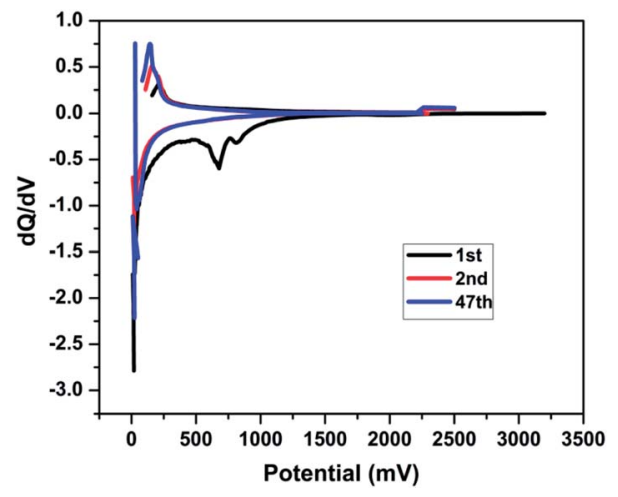

Fig. 7 Differential capacity curve for the 1st, 2nd and 47th cycles. solid/electrolyte interface (SEI) layer. The charge transfer resistance $\left(R_{\mathrm{CT}}\right)$ of the sample cell was calculated by extrapolating the semicircle, and the estimated value was $310 \Omega$. After cycling, the charge transfer resistance decreased to $295 \Omega$.

The impedance plot is fitted and the equivalent circuit is ascertained as shown in the inset to Fig. 8, and the values are tabulated in Table 2. It shows that for both sets of electrochemical impedance spectroscopy (EIS) data, the equivalent circuit is same. The capacitance $Q_{1}$ is in the order of $\mu \mathrm{F}$, which shows lower double layer capacitance at the electrode interface. The $R_{1}$ of 277.1 and $275 \Omega$ for the before and after cycling, respectively, shows that there is no significant change during the cycling process. Moreover, $C_{1}$ is the bulk capacitance of the material and $R_{2}$ is the leakage resistance.

The lithium diffusion coefficient is calculated from the lower frequency region by using the formula $D=R^{2} \times T^{2} / 2 A^{2} n^{4} F^{4} C^{2} \sigma^{2}$, where the $\sigma$ is calculated from the equation $Z_{\mathrm{re}}=R_{\mathrm{D}}+R_{\mathrm{L}}+\sigma \omega^{-1 / 2}$ by plotting $\omega^{-1 / 2}$ vs. $Z_{\mathrm{re}}$. Consequently, the diffusion coefficient values of both the EIS spectra are of the order of $10^{-17}$, which is ideal for the lithium diffusion at the electrode interface.

As can be seen from Table 1, G-CNT/phenolic composite paper prepared by carbonization at $1000{ }^{\circ} \mathrm{C}$ retains significant properties of CNTs (such as dc electrical conductivity, and mechanical strength). Most importantly, these samples show optimum values for conductivity, which is desired for exhibiting good microwave shielding response. Hence, one would expect that these materials could potentially be used in applications such as: the anode for a Li-ion battery, the anode for a fuel cell $^{21-23}$ and in EMI shielding devices. In view of the fact that our composite paper is a conductor and has good mechanical strength, we have studied its EMI shielding properties.

\section{Electromagnetic interference (EMI) shielding}

For EMI shielding measurements, the composite sample was inserted into the sample holder of size $15.8 \times 7.9 \mathrm{~mm}^{2}$. The SE was measured by calculating scattering parameters following the procedures reported earlier. ${ }^{17,24-31}$

Fig. 9 shows the variation of shielding effectiveness (SE) in the 12.4-18 GHz frequency range. The values of $\mathrm{SE}$ due to

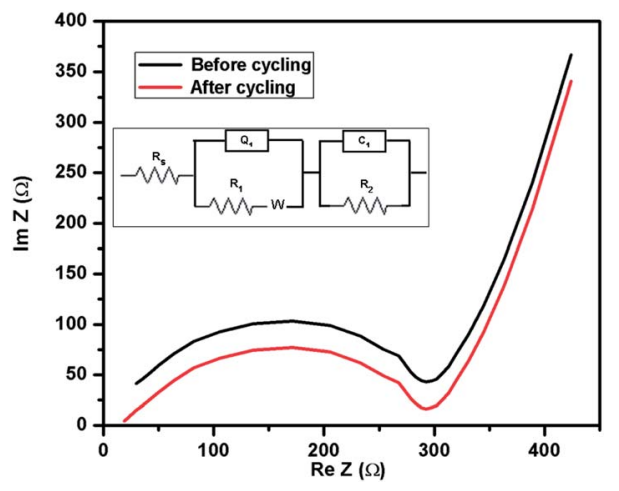

Fig. 8 Nyquist plot of the carbonised G-CNT/phenolic composite paper before and after cycling, and the inset shows the corresponding equivalent circuit. 
Table 2 EIS parameters of carbonised G-CNT/phenolic composite paper before and after cycling

\begin{tabular}{|c|c|c|c|c|c|c|c|c|}
\hline & $\mathrm{R}_{\mathrm{S}}(\mathrm{ohm})$ & $Q_{1}(\mu \mathrm{F})$ & $n$ & $R_{1}(\Omega)$ & $W$ & $C_{1}(\mathrm{mF})$ & $R_{2}(\Omega)$ & $\begin{array}{l}\text { Diffusion coefficient } \\
\left(\mathrm{cm}^{2} \mathrm{~s}^{-1}\right)\end{array}$ \\
\hline Before & 7.6 & 1.295 & 0.796 & 277.1 & 210 & 1.723 & 5078 & $1.36449 \times 10^{-17}$ \\
\hline After & 18.2 & 19.46 & 0.629 & 275 & 93.98 & 8.361 & 4300 & $1.27455 \times 10^{-17}$ \\
\hline
\end{tabular}

absorption ( $\left.\mathrm{SE}_{\mathrm{A}-\mathrm{NC}}\right)$ and reflection $\left(\mathrm{SE}_{\mathrm{R}-\mathrm{NC}}\right)$ for the non-carbonized G-CNT/phenolic composite paper are $20.9 \mathrm{~dB}$ and $9 \mathrm{~dB}$, respectively. Thus, the total $\mathrm{SE}_{\mathrm{T}-\mathrm{NC}}$ achieved for the noncarbonized G-CNT/phenolic composite paper is $29.9 \mathrm{~dB}$. For carbonized G-CNT/phenolic composite paper, $\mathrm{SE}_{\mathrm{A}-\mathrm{C}}$ and $\mathrm{SE}_{\mathrm{R}-\mathrm{C}}$ values were $17.9 \mathrm{~dB}$ and $14.5 \mathrm{~dB}$, respectively. Thus, the total $\mathrm{SE}_{\mathrm{T}-\mathrm{C}}$ for the carbonized composite paper is $32.4 \mathrm{~dB}$, which is significantly higher than the value for the non-carbonized paper. This is due to the significant enhancement in the electrical conductivity of the carbonized sample over the noncarbonized sample. Moreover, a SE value of around $20 \mathrm{~dB}$ is required for commercial EMI shielding applications; ${ }^{32}$ hence, our carbonized G-CNT/phenolic composite paper can be used for commercial EMI shielding applications.

The results suggest that $\mathrm{SE}_{\mathrm{T}}$ is mainly due to absorption, while the contribution from reflection $\left(\mathrm{SE}_{\mathrm{R}}\right)$ is less. The primary mechanism of EMI shielding is reflection of the electromagnetic radiation, which is a consequence of interaction of EMI radiation with the free electrons on the surface of the conducting shield..$^{33}$

The excellent shielding performance of carbonized composite paper is mainly attributed to two factors: impedance matching and EM wave attenuation. The presence of conducting MWCNTs in the insulating phenolic resin matrix results in the formation of a large number of interfaces and a heterogeneous system due to accumulation of space-charge at the interface, which contributes toward higher microwave shielding by the composites. Due to the differences in the conductivity of the MWCNTs and the resin, some charge carriers present in the MWCNTs get trapped, resulting in development of space-charge on the surface of the resin matrix. The contribution of ionic

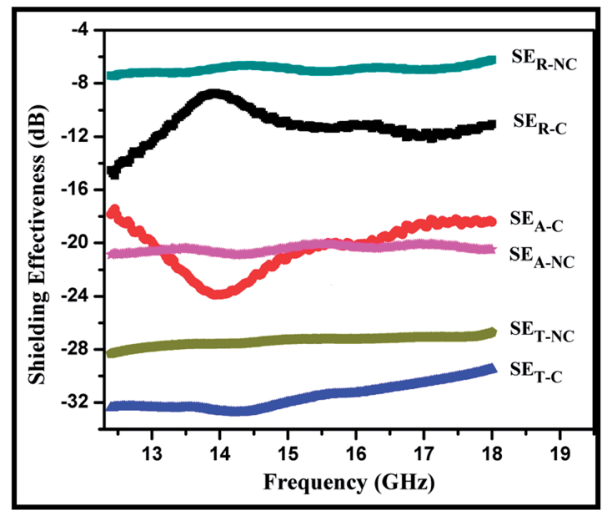

Fig. $9 \mathrm{EMI} \mathrm{SE}_{\mathrm{T}}, \mathrm{SE}_{\mathrm{A}}$ and $\mathrm{SE}_{\mathrm{R}}$ of $\mathrm{G}-\mathrm{CNT} /$ phenolic composite paper carbonized and non-carbonized as a function of frequency. conduction to the total loss becomes exceptionally higher with increased frequency. With an increase in frequency, the interfacial polarization decreases resulting in a decrease in the polarizability and loss factor. All these phenomena play crucial roles in the enhancement of microwave shielding. It may be proposed that the presence of MWCNTs in carbonized paper leads to a reduction of skin depth and increase in conductivity along with improvement in input impedance. This not only enhances the amount of electromagnetic radiation penetrating the shield but also increases the effective absorption capability. The presence of MWCNTs in phenolic resin results in (i) the formation of large number of interfaces, and (ii) a heterogeneous system due to the presence of space charge at the interface, which allows for impedance matching for better microwave shielding.

\section{Conclusion}

Strong, light-weight and free-standing MWCNT/phenolic composite paper was fabricated using a simple and novel dispersion technique. MWCNTs produced in-house by CVD were graphitized to improve its quality. The paper has very good electrical conductivity (76 $\mathrm{S} \mathrm{cm}^{-1}$ ) and bending strength (30 MPa) and can be used as an anode in LIBs without the need of copper as current collector, thus reducing the weight and increasing the energy density. It exhibits a stable reversible specific capacity for more that 45 cycles of operation. The thin paper (thickness $\sim 140 \mu \mathrm{m}$ ) shows an efficient electromagnetic shielding effectiveness of $32.4 \mathrm{~dB}$, which surpasses the value needed for commercial applications.

\section{Acknowledgements}

We are greatly thankful to Prof R. C. Budhani, Director CSIRNational Physical Laboratory, India, for taking interest in the work. We also thank Mr J. Tawale and Mr K. N. Sood for SEM measurements. We also extend our gratitude to Mr Jagdish Ghawana for carbonization of samples, Mrs Shaveta Sharma for flexural strength measurements and Mr R. K. Seth for the BET test. This work was carried under CSIR-TAPSUN (NWP 56) project on "Innovative Solution for Solar Energy Storage".

\section{References}

1 N. A. Kaskhedikar and J. Maier, Adv. Mater., 2009, 21, 26642680.

2 W. Lu, A. Goering, L. Qu and L. Dai, Phys. Chem. Chem. Phys., 2012, 14, 12099-12104. 
3 C. Kang, I. Lahiri, R. Baskaran, W.-G. Kim, Y.-K. Sun and W. Choi, J. Power Sources, 2012, 219, 364-370.

4 D. T. Welna, L. Qu, B. E. Taylor, L. Dai and M. F. Durstock, J. Power Sources, 2011, 196, 1455-1460.

5 B. J. Landi, M. J. Ganter, C. D. Cress, R. A. DiLeo and R. P. Raffaelle, Energy Environ. Sci., 2009, 2, 638-654.

6 V. Choudhary, B. Singh and R. Mathur, Carbon Nanotubes and Their Composites, Syntheses and Applications of Carbon Nanotubes and Their Composites, ed. S. Suzuki, 2013, pp. 978-953, ISBN.

7 B. J. Landi, R. A. Dileo, C. M. Schauerman, C. D. Cress, M. J. Ganter and R. P. Raffaelle, J. Nanosci. Nanotechnol., 2009, 9, 3406-3410.

8 B. P. Singh, P. V. Choudhary, P. Saini, S. Pande, V. N. Singh and R. B. Mathur, J. Nanopart. Res., 2013, 15, 1-12.

9 B. L. Wardle, D. S. Saito, E. J. García, A. J. Hart, R. G. de Villoria and E. A. Verploegen, Adv. Mater., 2008, 20, 27072714.

10 J. Gou, Polym. Int., 2006, 55, 1283-1288.

11 Z. Wang, Z. Liang, B. Wang, C. Zhang and L. Kramer, Composites, Part A, 2004, 35, 1225-1232.

12 Q.-P. Feng, J.-P. Yang, S.-Y. Fu and Y.-W. Mai, Carbon, 2010, 48, 2057-2062.

13 Q.-P. Feng, X.-J. Shen, J.-P. Yang, S.-Y. Fu, Y.-W. Mai and K. Friedrich, Polymer, 2011, 52, 6037-6045.

14 P. D. Bradford, X. Wang, H. Zhao, J.-P. Maria, Q. Jia and Y. T. Zhu, Compos. Sci. Technol., 2010, 70, 1980-1985.

15 T. Ogasawara, S.-Y. Moon, Y. Inoue and Y. Shimamura, Compos. Sci. Technol., 2011, 71, 1826-1833.

16 R. B. Mathur, S. Chatterjee and B. P. Singh, Compos. Sci. Technol., 2008, 68, 1608-1615.

17 B. P. Singh, K. Saini, V. Choudhary, S. Teotia, S. Pande, P. Saini and R. B. Mathur, J Nanopart Res, 2014, 16, 2161.
18 R. B. Mathur, P. H. Maheshwari, T. L. Dhami, R. K. Sharma and C. P. Sharma, J. Power Sources, 2006, 161, 790-798.

19 R. Rao, R. Podila, R. Tsuchikawa, J. Katoch, D. Tishler, A. M. Rao and M. Ishigami, ACS Nano, 2011, 5, 1594-1599.

20 S. Santangelo, G. Messina, G. Faggio, M. Lanza and C. Milone, J. Raman Spectrosc., 2011, 42, 593-602.

21 Z. Q. Tian, S. P. Jiang, Y. M. Liang and P. K. Shen, J. Phys.Chem. B, 2006, 110, 5343-5350.

22 M. M. Shaijumon, S. Ramaprabhu and N. Rajalakshmi, Appl. Phys. Lett., 2006, 88, 253105.

23 A. P. Singh, B. K. Gupta, M. Mishra, G. A. Chandra, R. B. Mathur and S. K. Dhawan, Carbon, 2013, 56, 86-96.

24 P. Saini, V. Choudhary, B. Singh, R. Mathur and S. Dhawan, Mater. Chem. Phys., 2009, 113, 919-926.

25 T. K. Gupta, B. P. Singh, V. N. Singh, S. Teotia, A. P. Singh, I. Elizabeth, S. R. Dhakate, S. K. Dhawan and R. B. Mathur, J. Mater. Chem. A, 2014, 2, 4256-4263.

26 T. K. Gupta, B. P. Singh, R. B. Mathur and S. R. Dhakate, Nanoscale, 2014, 6, 842-851.

27 A. P. Singh, M. Mishra, P. Sambyal, B. K. Gupta, B. P. Singh, A. Chandra and S. K. Dhawan, J. Mater. Chem. A, 2014, 2, 3581-3593.

28 T. K. Gupta, B. P. Singh, S. R. Dhakate, V. N. Singh and R. B. Mathur, J. Mater. Chem. A, 2013, 9138-9149.

29 T. K. Gupta, B. P. Singh, S. Teotia, V. Katyal, S. R. Dhakate and R. B. Mathur, J. Polym. Res., 2013, 20, 1-7.

30 K. Singh, A. Ohlan, V. H. Pham, R. Balasubramaniyan, S. Varshney, J. Jang, S. H. Hur, W. M. Choi, M. Kumar and S. Dhawan, Nanoscale, 2013, 5, 2411-2420.

31 B. P. Singh, V. Choudhary, P. Saini and R. B. Mathur, AIP Adv., 2012, 2, 022151.

32 N. Li, Y. Huang, F. Du, X. He, X. Lin, H. Gao, Y. Ma, F. Li, Y. Chen and P. C. Eklund, Nano Lett., 2006, 6, 1141-1145.

33 D. D. L. Chung, Carbon, 2001, 39, 279-285. 